\title{
Validation of a Real-Time Polymerase Chain Reaction Assay for the Identification of Meloidogyne arenaria
}

Paula Agudelo, Stephen A. Lewis, and Bruce A. Fortnum, Department of Entomology, Soils, and Plant Sciences, Clemson University, Clemson, SC 29634

\begin{abstract}
Agudelo, P., Lewis, S. A., and Fortnum, B. A. 2011. Validation of a real-time polymerase chain reaction assay for the identification of Meloidogyne arenaria. Plant Dis. 95:835-838.

Meloidogyne arenaria is an economically important parasite of many crops worldwide. Identification and detection of this species in soil samples is necessary for the design of crop rotation systems, selection of resistant cultivars, and potential use of biological control options. The objective of this study was to develop and validate a real-time polymerase chain reaction (PCR) assay, using species-specific primers and SYBR Green I Dye, for identification of M. arenaria. The specificity of the assay was confirmed by testing for amplification of DNA

from other Meloidogyne spp. and from M. arenaria populations of different geographic origins. Field soil samples containing a mixture of $M$. arenaria and $M$. incognita were used to compare identification by the real-time PCR assay with identification by esterase phenotype analysis of mature females and by morphometrics of juveniles. The real-time PCR assay provided an accurate and sensitive means for the identification of single juveniles from soil samples.
\end{abstract}

Meloidogyne arenaria (Neal 1889) Chitwood 1949 is an economically important parasite of many crops worldwide, often found in mixtures with other root-knot nematode species $(3,6,12,18)$. Several nonchemical control methods, including cultivar resistance, crop rotation, and biological control, are species specific. In order to make effective use of these strategies, methods that enable timely detection and identification of the infective juvenile stages present in the soil are needed. Polymerase chain reaction (PCR)-based techniques are ideal for this purpose because of application to all life stages of the nematode, and for having the sensitivity required to detect mixtures of closely related species. Several PCR-based assays have been developed for identification of a number of Meloidogyne spp. (1,4,13,20,23-25). However, the high intraspecific variability of $M$. arenaria and its evolutionary closeness to $M$. incognita and $M$. javanica have limited the usefulness of genetic regions commonly utilized for diagnostics of other plant-parasitic nematodes, such as the ribosomal RNA array $(5,7,14,19)$. Nevertheless, several anonymous loci have been evaluated in studies of inter- and intraspecific genetic variation of $M$. arenaria, $M$. incognita, and $M$. javanica $(3,6,7)$, and random amplified polymorphic DNA (RAPD) markers have been converted to species-specific sequence-characterized amplified region (SCAR)PCR assays $(8,24)$.

Species-specific markers can be used in real-time PCR assays for identification, detection, or quantification purposes with a wide variety of applications. Real time-PCR combines the sensitivity of conventional PCR with the generation of a specific fluorescent signal, which can be measured throughout the procedure, providing real-time analysis of the reaction kinetics and allowing quantification of specific DNA targets (22). There are increasing reports of its use in plant nematology, and considerable success has been obtained in alleviating some of the challenges associated with detection of soilborne pathogens $(2,16,17)$.

The objectives of this study were to develop a real-time PCR assay for identification of $M$. arenaria, and to compare this diagnos-

Corresponding author: P. Agudelo, E-mail: pagudel@clemson.edu

Accepted for publication 8 March 2011.

doi:10.1094/PDIS-09-10-0668

(C) 2011 The American Phytopathological Society tic tool with other methods of identifying root-knot nematodes from field soil samples containing mixtures of $M$. arenaria and $M$. incognita populations.

\section{Materials and Methods}

Nematodes. The Meloidogyne populations used in this study (Table 1) belong to the International Meloidogyne Project collection, housed by Clemson University. Each accession in this collection has been identified based on morphology (perineal patterns and morphometrics), and the identifications have been verified by isozyme phenotyping prior to their storage in liquid nitrogen. DNA was extracted from individual juveniles by using the Sigma Extract-N-Amp kit (XNAT2; Sigma-Aldrich, St. Louis). The manufacturer's protocol for animal tissue was modified as follows. One second-stage juvenile was transferred into a $0.2-\mathrm{ml}$ centrifuge tube containing $10 \mu \mathrm{l}$ of the kit's extraction solution. The nematode was then crushed using the tip of a $<10-\mu 1$ pipette tip, followed by addition of $2.5 \mu \mathrm{l}$ of the kit's tissue prep solution. The tube was then vortexed, followed by a brief centrifugation to collect contents. The suspension was incubated at $55^{\circ} \mathrm{C}$ for 10 min and then at $95^{\circ} \mathrm{C}$ for $3 \mathrm{~min}$. Next, $10 \mu \mathrm{l}$ of the kit's neutralization solution was added. DNA concentrations were determined by spectrophotometry in a BioPhotometer Plus (Eppendorf, Hamburg, Germany).

Table 1. Populations and species used to validate the specificity of the realtime polymerase chain reaction (PCR) assay for identification of Meloidogyne arenaria

\begin{tabular}{lllc}
\hline IMPa & \multicolumn{1}{c}{ Species } & \multicolumn{1}{c}{ Geographic origin } & $\begin{array}{c}\text { Ct value } \\
(\boldsymbol{n}=\mathbf{9})^{\mathbf{b}}\end{array}$ \\
\hline 1842 & M. arenaria $($ race 2) & Ontario, Canada & 27.32 \\
3145 & M. arenaria $($ race 1) & Georgia, United States & 28.45 \\
4077 & M. arenaria $($ race 2) & South Carolina, United States & 27.12 \\
0615 & M. arenaria $($ race 1) & Texas, United States & 27.94 \\
2939 & M. arenaria $($ race 2) & North Carolina, United States & 28.07 \\
2714 & M. incognita $($ race 3) & South Carolina, United States & 0 \\
3695 & M. incognita $($ race 1) & North Carolina, United States & 0 \\
0196 & M. javanica & North Carolina, United States & 0 \\
2674 & M. hapla & North Carolina, United States & 0 \\
4501 & M. chitwoodi & Washington, United States & 0 \\
\hline
\end{tabular}

${ }^{a}$ International Meloidogyne Project (IMP) collection accession number.

${ }^{b}$ Average threshold cycle value $(\mathrm{Ct})$ was obtained from three independent runs for three individual juveniles. 
Real-time PCR assay. A SCAR marker (950-bp amplicon) previously identified in our lab (8) as species specific for $M$. arenaria (GenBank accession AF387098) was used as a starting point to design several primer pairs amplifying shorter fragments (adequate for real-time PCR) within this region, using Primer 3 software (21). The primer selection criteria included amplicon size (between 100 and $200 \mathrm{bp}$ ), primer length (18 to $22 \mathrm{bp}$ ), melting temperature $\left(55\right.$ to $65^{\circ} \mathrm{C}$ ), GC content (between 40 and $80 \%$ ), and absence of secondary structure. Specific primers were designed so that the nucleotides unique to the target were at the $3^{\prime}$ end position of the primer. The putative primers were tested by conventional PCR and analyzed using agarose gel separation to ensure that specificity was maintained and that the PCR product was a single band. Out of several possible primer combinations, the pair chosen was QareF 5'-TCCATTTCTCCTTGGGTTTG-3' and QareR 5'GCCATCCCTTCACACGTTAT-3'. These primers amplify a DNA fragment of $158 \mathrm{bp}$ within the 950-bp SCAR marker (primers underlined): 5'-TCCATTTCTCCTTGGGTTTGTATTGCGCTGGTA ATAAGGGCACATTGTTCATGAGTTTTTACTTAAAAAGGAA ATTTCTTTAAAAGAAATTTTTCTTCAGAGCAGTTCAGCTCA TGTCAGTCCTACGTTCAGTCCCGTATAACGTGTGAAGGGA TGGC-3'.

The specificity of this selected amplicon was also preliminarily assessed by means of basic local alignment search tool (BLAST) analysis. Subsequently, amplifications were performed in real time using a Smart Cycler II (Cepheid, Sunnyvale, CA). The specificity of the primer pair was validated using genomic DNA from $M$. arenaria populations from different geographic origins, and $M$. incognita, M. javanica, M. hapla, and M. chitwoodi (Table 1). Negative controls, using PCR-grade water instead of DNA template, were included in all runs. Primers that amplify a partial sequence of the $28 \mathrm{~S}$ ribosomal RNA gene common to most Meloidogyne spp. (19) were used for concomitant generic reactions to ensure that the DNA extracts were adequate for PCR. This generic positive control also verified that reactions negative for $M$. arenaria were true negatives and not failed reactions.

Amplification reactions were performed in a final volume of 25 $\mu \mathrm{l}$, with $2 \mu \mathrm{l}$ of DNA extract, $0.2 \mu \mathrm{M}$ each primer, and $14 \mu \mathrm{l}$ of SYBR Green Jump Start Taq Ready Mix (Sigma-Aldrich), containing $20 \mathrm{mM}$ Tris- $\mathrm{HCl}(\mathrm{pH} \mathrm{8.3)}, 100 \mathrm{mM} \mathrm{KCl}, 7 \mathrm{mM} \mathrm{MgCl} 2,0.4$ $\mathrm{mM}$ each dNTP, Taq DNA polymerase at 0.05 unit/ $\mu 1$, Jump Start Taq antibody, and SYBR Green I dye. The protocol used was an initial denaturation at $95^{\circ} \mathrm{C}$ for $300 \mathrm{~s}$, followed by 40 cycles of denaturation at $95^{\circ} \mathrm{C}$ for $5 \mathrm{~s}$, annealing at $60^{\circ} \mathrm{C}$ for $30 \mathrm{~s}$, and extension at $72^{\circ} \mathrm{C}$ for $5 \mathrm{~s}$. Fluorescence was read after each cycle. The default setting of 30 fluorescent units of the Smart Cycler II software was used as threshold. Any sample reaching a fluorescence value exceeding this threshold was considered positive, and the PCR cycle at which this fluorescence was reached was considered the cycle threshold $(\mathrm{Ct})$. DNA melting curve analysis of the resulting amplicon was performed at the end of amplification, by cooling the samples to $60^{\circ} \mathrm{C}$ and then increasing the temperature to $95^{\circ} \mathrm{C}$ at $0.2^{\circ} \mathrm{C} / \mathrm{s}$. For verification, PCR products were purified and sent to the Clemson University Genomics Institute (Clemson, SC) for

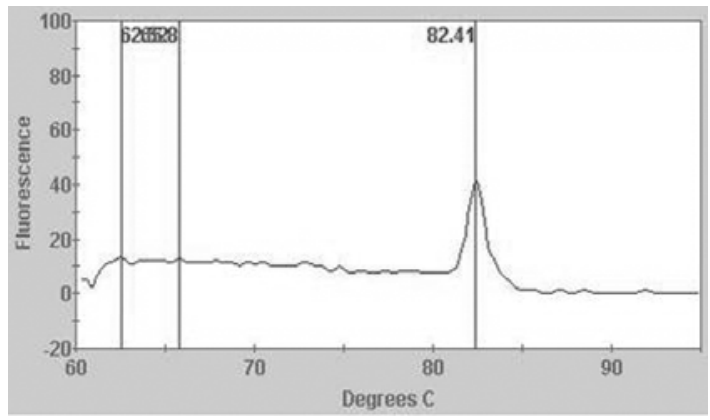

Fig. 1. Signature melting curve for the target amplicon, with melting point of $82.41^{\circ} \mathrm{C}$. direct sequencing in both directions. Amplification primers were used as sequencing primers.

To generate a standard curve, three independent DNA extractions were performed from 1,000 juveniles of $M$. arenaria. The extracted DNA was then serially diluted three times 10 -fold $\left(10^{-1}\right.$ to $10^{-4}$ ) with PCR-grade sterile distilled water. The three series of DNA dilutions were used in three independent runs of real-time PCR reactions as described above. The Ct values obtained from the real-time PCR runs were used to generate standard curves. To evaluate consistency and reproducibility between replicates of DNA, standard deviations between and within PCR runs were evaluated using the statistical software SAS (ver. 9.1.3; SAS Institute Inc., Cary, NC).

Field soil samples. Soil samples were collected from a field naturally infested with $M$. arenaria and $M$. incognita, located in Florence County, SC, at Pee Dee Research and Education Center, Clemson University. This field has been used for several years to perform studies on the effect of crop rotation on population densities of these two species $(11,12)$. Half of the field area was planted with corn and the other half with soybean, both grown using standard production and pest control practices recommended by Clemson University Cooperative Extension Service. These two crops were used to produce field soils that were predominantly infested with one or the other species, while maintaining the second species at very low levels. Previous studies in this field have established that corn favors the reproduction of $M$. incognita while soybean will increase the density of $M$. arenaria $(11,12)$.

Comparison of identification methods. A portion of each soil sample $\left(50 \mathrm{~cm}^{3}\right)$ was used for extraction of juveniles by centrifugal flotation (15), and the rest $\left(250 \mathrm{~cm}^{3}\right)$ was used to grow mature females. Tomato (Lycopersicon esculentum L. 'Rutgers') seedlings were transplanted into pots containing the soil from each sample and maintained in the greenhouse. After 50 days, 20 adult females per sample were hand picked from roots for esterase phenotype analysis (10) using a Phastsystem automated electrophoresis unit (Pharmacia, Piscataway, NJ). Ten additional mature females per sample were picked from the same tomato roots for DNA extraction by the method described above and species determination by the real-time PCR assay.

Twenty juveniles from each of the 10 soil samples were examined by light microscopy on temporary glass slides and identified by morphology (9). Temporary slides were dismantled and the nematodes individually placed in a microcentrifuge tube for DNA extraction for species determination by the real-time PCR assay.

\section{Results and Discussion}

Primer specificity was confirmed by amplification of a DNA fragment of the expected size ( $158 \mathrm{bp})$ and the increase of the fluorescence signal for all the populations of $M$. arenaria but not for the other species. Melting curve and gel analysis confirmed the presence of only one specific amplicon (melting temperature = $82.41^{\circ} \mathrm{C}$; Fig. 1). The analyses did not reveal any primer dimers that could affect the accuracy of the real-time PCR reactions. Of the $22.5 \mu \mathrm{l}$ of total DNA extracted from a single juvenile, $2 \mu \mathrm{l}$ yielded stable $\mathrm{Ct}$ values, averaging 27.32, 28.45, 27.12, 27.94, and 28.07 for each of the five $M$. arenaria populations tested, respectively (Table 1).

Using the specific primers, increase in fluorescence was only detected in samples containing $M$. arenaria. For the standard curve, the $\mathrm{Ct}$ value increased with the degree of dilution of the DNA samples, with the highest dilution $\left(10^{-4}\right)$ having the highest $\mathrm{Ct}$ values (33.0; Fig. 2). The standard curve generated from the three sets of dilutions had a nearly perfect negative relationship between cycle number and the log DNA concentration (Fig. 3), and little variation between replicated samples and runs. The standard deviation of $\mathrm{Ct}$ values of three different sample preparations and of different runs of the samples ranged from 0.01 to 0.09 . The slope of the standard curves ranged between -3.29 and -3.57 and $r^{2}$ values between 0.98 and 0.99. These results demonstrate that amplifications were highly reproducible. 
Identification of the vermiform stages directly from the soil gave a more accurate representation of the species present in the samples than identification of mature females after culturing the populations on tomato. This is expected because the bioassay is a more indirect way of identification and there is the possibility of altering the original composition of species frequencies. Several $M$. arenaria individuals were identified in the soil samples from corn that were not detected by the methods applied to females (Table 2). In sample 1 with soybean, two non-M. arenaria juveniles were detected which the female assay did not detect. The esterase phenotyping of females only detected species mixtures in corn in one of six samples and none of the soybean samples. Real-time PCR of females detected species mixtures in three of six samples in corn and none of the soybean samples. Juvenile identification

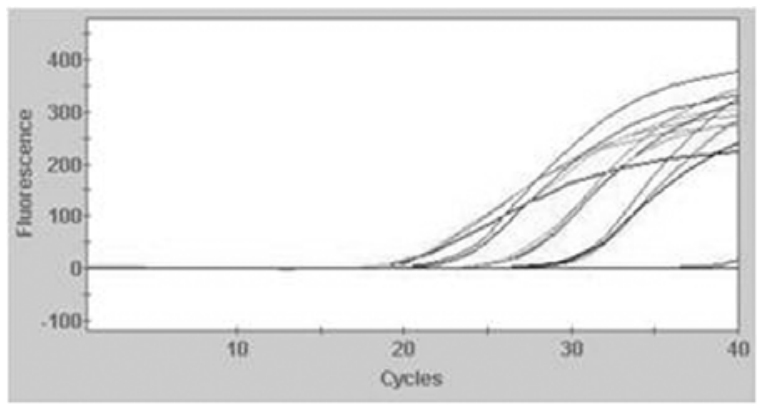

Fig. 2. Amplification curves of 10 -fold serial dilutions of DNA from 1,000 nematodes in real-time polymerase chain reaction (PCR) with primers specific to Meloidogyne arenaria. Assays were conducted three times for each dilution, using $2 \mu \mathrm{l}$ of DNA template under optimized real-time PCR conditions.

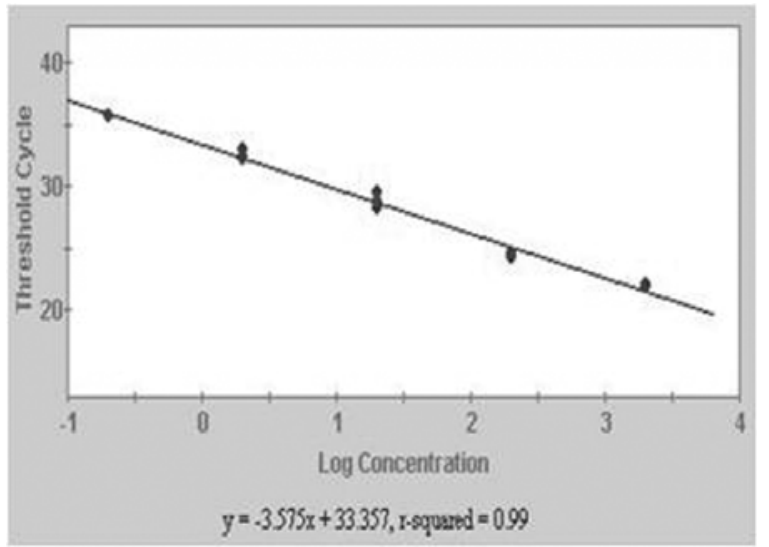

Fig. 3. Standard curve for Meloidogyne arenaria using the species-specific realtime polymerase chain reaction assay. The curve was generated from 10 -fold serial dilutions $\left(10^{1}\right.$ to $\left.10^{4}\right)$ of DNA extracted from 1,000 juveniles $(y=-3.575 x+33.357$; $\left.R^{2}=0.99\right)$. methods detected species mixtures in one of the soybean samples and three of the corn samples. Out of 200 juveniles examined from the 10 soil samples, 97 were identified by morphology as $M$. arenaria (78 in soybean and 19 in corn) and 103 as not $M$. arenaria ( 2 in soybean and 101 in corn). The real-time PCR assay identified 92 of 97 as $M$. arenaria $(94.8 \%$ correspondence with morphology) and correctly gave negative results for all $103 \mathrm{M}$. incognita (or not- $M$. arenaria) for $100 \%$ correspondence with identification by morphology.

Correspondence between the data obtained by esterase phenotype analysis and real-time PCR of females is difficult to assess because reactions were not performed on the same individuals. Nevertheless, results were very similar, except for soil samples 8 and 10, where seven and four females, respectively, were identified as $M$. arenaria by PCR (Table 2). Isozyme analysis has been used for identification of several Meloidogyne spp. but this technique relies on the expression of a gene product (10) occurring in mature females. This stage is not often found in soil samples, where second-stage juveniles are more prevalent. Additionally, one female is needed for each reaction, with no opportunity for replicates with the same individual, whereas, in the real-time PCR assay developed, DNA from a single juvenile can be used for over 20 reactions. The other limitation of female isozyme analysis is that it is not always conclusive. Esterase analysis, for example, can yield three different profiles for $M$. arenaria populations and it is estimated that only $84 \%$ of populations can be characterized by this method (10). Although isozyme expression continues to be a valuable taxonomic tool, we believe that DNA diagnostic methods provide higher reliability and overcome the limitations of enzyme phenotyping.

Some PCR-based nematode identification methods in the literature use specimens manually disrupted with a micropipette tip as template for amplification (13). We do not recommend this method of template preparation for real-time PCR applications because the quality of the template is critical for successful reactions. The DNA extraction method used in this study adds $15 \mathrm{~min}$ to the identification procedure compared with using manually disrupted specimens but provides good-quality templates for many reactions.

The difficulty in identifying the different root-knot nematode species in routine nematode soil assays has often prevented farmers from using plant resistance and other species-specific methods effectively. Perineal patterns, thorough morphological observations, and isozyme analyses require mature females. Often, clinic samples contain only juveniles and eggs; therefore, culturing on susceptible hosts before species identification can be conducted if necessary. We have developed and validated a real-time PCR assay that provides a diagnostic tool for $M$. arenaria juveniles directly from soil samples and limits the need for expertise for nematode identification. Compared with conventional PCR methods, this real-time PCR assay also allows faster identification but, more importantly, it has the potential to be optimized and adapted for simultaneous detection and quantification of $M$. arenaria individu-

Table 2. Number of females and juveniles identified as Meloidogyne arenaria by esterase phenotype analysis, morphological identification, and real-time polymerase chain reaction (PCR) assay based on 10 soil samples from a field in Florence, SC

\begin{tabular}{|c|c|c|c|c|c|}
\hline \multirow[b]{2}{*}{ Sample } & \multicolumn{2}{|c|}{ Females after bioassay } & \multicolumn{3}{|c|}{ Juveniles from soil } \\
\hline & Esterase phenotype $(n=20)$ & Real-time PCR $(n=10)$ & Morphology $(n=20)$ & Real-time PCR $(n=20)$ & Agreement $(\%)^{\mathrm{a}}$ \\
\hline 1 Soybean & 20 & 10 & 18 & 18 & 100 \\
\hline 2 Soybean & 19 & 10 & 20 & 19 & 95 \\
\hline 3 Soybean & 20 & 10 & 20 & 19 & 95 \\
\hline 4 Soybean & 19 & 10 & 20 & 17 & 85 \\
\hline 5 Corn & 0 & 0 & 3 & 3 & 100 \\
\hline 6 Corn & 0 & 0 & 0 & 0 & 100 \\
\hline 7 Corn & 6 & 6 & 8 & 8 & 100 \\
\hline 8 Corn & 0 & 7 & 6 & 6 & 100 \\
\hline 9 Corn & 0 & 0 & 0 & 0 & 100 \\
\hline 10 Corn & 0 & 4 & 2 & 2 & 100 \\
\hline
\end{tabular}

${ }^{a}$ Percent agreement was calculated by dividing the number of positive $M$. arenaria juvenile identifications made by PCR by the number of $M$. arenaria identifications made by morphology. 
als in soil samples, or to allow the use of portable real-time PCR devices for on-site field diagnosis. Given its specificity, sensitivity, and reliability, this assay can be of benefit to phytosanitary services and a valuable decision management tool for growers.

\section{Literature Cited}

1. Blok, V., Wishart, J., Fargette, M., Bertier, K., and Phillips, M. S. 2002. Mitochondrial DNA differences distinguishing Meloidogyne mayaguensis from the major species of tropical root-knot nematodes. Nematology 4:773-781.

2. Cao, A. X., Lui, X. Z., Zhu, S. F., and Lu, B. S. 2005. Detection of the pinewood nematode, Bursaphelenchus xylophilus, using a real-time polymerase chain reaction assay. Phytopathology 95:566-571.

3. Carneiro, R. M. D. G., Tigano, M. S., Randig, O., Almeida, M. R. A., and Sarah, J. L. 2004. Identification and genetic diversity of Meloidogyne spp. (Tylenchida: Meloidogynidae) on coffee from Brazil, Central America and Hawaii. Nematology 6:287-298.

4. Cenis, J. L. 1993. Identification of four major Meloidogyne spp. as shown by random amplified polymorphic DNA (RAPD-PCR). Phytopathology 83:76-78.

5. Chen, P., Roberts, P. A., Metcalf, A. E., and Hyman, B. C. 2003. Nucleotide substitution patterning within the Meloidogyne rDNA D3 region and its evolutionary implications. J. Nematol. 35:404-410.

6. Cofcewicz, E. T., Carneiro, R. M. D. G., Castagnone-Sereno, P., and Queneherve, P. 2004. Enzyme phenotypes and genetic diversity of root-knot nematodes parasitizing Musa in Brazil. Nematology 6:85-95.

7. Dautova, M., Overmars, H., Bakker, J., Smant, G., and Gommers, F. J. 2002. Nuclear and mitochondrial DNA polymorphisms in three mitotic parthenogenetic Meloidogyne spp. Eur. J. Plant Pathol.108:209-220.

8. Dong, K., Dean, R. A., Fortnum, B. A., and Lewis, S. A. 2001. Development of PCR primers to identify species of root-knot nematodes: Meloidogyne arenaria, $M$. hapla, $M$. incognita and $M$. javanica. Nematropica 31:273-282.

9. Eisenback, J. D., Hirschmann, H., Sasser, J. N., and Triantaphyllou, A. C. 1981. A Guide to the Four Most Common Species of Root-Knot Nematodes, (Meloidogyne species) with a Pictorial Key. A Coop. Publ. Departments of Plant Pathology and Genetics and U.S. Agency for International Development, Raleigh, NC.

10. Esbenshade, P. R., and Triantaphyllou, A. C. 1985. Identification of major Meloidogyne species employing enzyme phenotypes as differentiating characters. Pages 135-140 in: An Advanced Treatise on Meloidogyne. K. R. Barker, C. C. Carter, and J. N. Sasser, eds. North Carolina State University Graphics, Raleigh.
11. Fortnum, B. A., and Currin, R. E. 1993. Crop rotation and nematicides effects on the frequency of Meloidogyne spp. in a mixed population. Phytopathology 83:350-355.

12. Fortnum, B. A., Lewis, S. A., and Johnson, A. W. 2001. Crop rotation and nematicides for management of mixed populations of Meloidogyne spp. on tobacco. J. Nematol. 4S:318-324.

13. Harris, T. S., Sandall, L. J., and Powers, T. O. 1990. Identification of single Meloidogyne juveniles by polymerase chain reaction amplification of mitochondrial DNA. J. Nematol. 22:518-524.

14. Hugall, A., Stanton, J., and Moritz, C. 1999. Reticulate evolution and the origins of ribosomal internal transcribed spacer diversity in apomictic Meloidogyne. Mol. Biol. Evol. 16:157-164.

15. Jenkins, W. R. 1964. A rapid centrifugal-flotation method for separating nematodes from soil. Plant Dis. Rep. 48:692.

16. Madani, M., Subbotin, S. A., and Moens, M. 2005. Quantitative detection of the potato cyst nematode, Globodera pallida, and the beet cyst nematode Heterodera schachtii, using real-time PCR with SYBR green I dye. Mol. Cell Probes 19:81-86.

17. Nakhla, M. K., Owens, K. J., Li, W., Wei, G., Skantar, A. M., and Levy, L. 2010. Multiplex real-time PCR assays for the identification of the potato cyst and tobacco cyst nematodes. Plant Dis. 94:959-965.

18. Navas, A., Castagnone-Sereno, P., Blasquez, J., and Esparrago, G. 2001 Genetic structure and diversity within local populations of Meloidogyne (Nematoda: Meloidogynidae). Nematology 3:243-253.

19. Powers, T. O. 2004. Nematode molecular diagnostics: from bands to barcodes. Annu. Rev. Phytopathol. 42:367-383.

20. Powers, T. O., and Harris, T. S. 1993. A polymerase chain reaction method for identification of five major Meloidogyne species. J. Nematol. 25:1-6.

21. Rozen, S., and Skaletsky, H. J. 2000. Primer3 on the WWW for genera users and for biologist programmers. Pages 365-386 in: Bioinformatics Methods and Protocols: Methods in Molecular Biology. S. Krawetz and S. Misener, eds. Humana Press, Totowa, NJ.

22. Schmittgen, T. D. 2001. Real-time quantitative PCR. Methods 25:383-385.

23. Stanton, J., Hugall, A., and Moritz, C. 1997. Nucleotide polymorphisms and an improved PCR-based mtDNA diagnostic for parthenogenetic root-knot nematodes (Meloidogyne spp.). Fundam. Appl. Nematol. 20:261-268.

24. Zijlstra, C., Donkers-Venne, D. T. H. M, and Fargette, M. 2000. Identification of Meloidogyne incognita, M. javanica and M. arenaria using sequence characterized amplified region (SCAR) based PCR assays. Nematology 2:847-853.

25. Zijlstra, C., Uenk, B. J., and Van Silfhout, C. H. 1997. A reliable, precise method to differentiate species of root-knot nematode in mixtures on the basis of ITS-RFLPs. Fundam. Appl. Nematol. 20:59-63. 